\title{
ARTE, MEMÓRIA E DIREITOS HUMANOS
}

Fulvia Molina

Escola de Comunicações e Artes da Universidade de São Paulo (ECA - USP), São Paulo, SP - Brasil. Instituto de Biociências da Universidade de São Paulo (IB - USP), São Paulo, SP - Brasil. <fulvia.molina@terra.com.br>

http://dx.doi.org/10.1590/ 0102-64450101-115/96

Quando Antígona, a heroína da tragédia que leva o seu nome, é obrigada a decidir sobre o destino do corpo do irmão morto, ela o faz contra as determinações do rei de Tebas, seu tio Creonte. Mesmo sabendo que seria condenada à morte pela transgressão, ela decide sepultá-lo. Surpreendida pelos guardas, que vigiavam o cadáver insepulto de Polinices, Antígona é presa e levada à presença de Creonte. Segue-se, então, o diálogo entre eles:

CREONTE - E ousaste, então, tripudiar sobre estas leis? ANTÍGONA - É que estas não foi Zeus que as promulgou, nem a Justiça, que coabita com os deuses infernais, estabeleceu tais leis para os homens. E eu entendi que os teus éditos não tinham tal poder, que um mortal pudesse sobrelevar os preceitos, não escritos, mas imutáveis dos deuses. Porque esses não são de agora, nem de ontem, mas vigoram sempre, e ninguém sabe quando surgiram. Por causa das tuas leis, não queria eu ser castigada, perante os deuses, por ter temido a decisão de um homem. (Sófocles, 2012 [c. 440 a.C.], p. 67) 
Aqui Antígona age segundo o que considera ser seu dever de irmã, seu imperativo ético pelas leis divinas em oposição às leis humanas. Vemos, também, já claramente colocado nessa obra de Sófocles, uma peça teatral escrita há 2500 anos, o conflito ético central de nossa civilização: o conflito entre a razão da consciência e a razão do Estado.

No centro da cena trágica está expressada a razão de consciência, desnudando a razão do Estado. A arte, a poiesis, emerge como a verdade do artista, a sua alétheia, o seu ato ético por excelência, com suas razões e contradições, ato que resulta de sua decisão solitária. O que está em jogo para o artista, nessa hora, é a sua vida ou a sua morte, ou, ao menos, a sua saúde espiritual, na expressão de Giorgio Agamben (2012, p. 23).

A razão do Estado, por outro lado, é a razão sempre invocada pelo poder dominante para justificar suas leis, mesmo as mais abusivas, até o extremo de instaurar o Estado

102 de exceção, em que o soberano tem o poder legal de suspender a validade da lei, colocando-se legalmente fora da lei, e afirmando que não é um fora da lei. A excessão é uma espécie de exclusão. É a redução da pessoa humana à "pura vida nua”, na expressão de Agamben (2002, p. 23), em que o indivíduo é considerado como pura vida biológica, despido de todo direito humano.

Paradoxalmente, mesmo os modernos Estados democráticos de direito ainda têm embutidas em suas constituições as provisões do Estado de exceção. Essa é a atual situação dos Estados Unidos com as leis USA Patriot Act (2001) e Homeland Security Act (2002). Essas leis passaram no Congresso daquele país no calor dos ataques de 11 de setembro de 2001; elas estabelecem que as pessoas consideradas inimigas do Estado podem ser presas como "combatentes inimigos", sem os direitos comuns aos outros cidadãos, como calar-se em juízo, ser assistido por um advogado e não permanecer preso sem culpa formada. É o caso das centenas 
de pessoas ainda mantidas presas em Guantánamo, há anos, sem perspectiva de julgamento.

É nesse contexto que a arte contemporânea vem cumprir um papel ético, ao revisitar os fatos portadores de dor. Tem o dom de atualizá-los e de fazer aflorar as indagações necessárias sobre

[...] quais os procedimentos jurídicos e quais os dispositivos políticos que permitiram que seres humanos fossem tão integralmente privados de seus direitos e de suas prerrogativas, até o ponto em que cometer contra eles qualquer ato não mais se apresentasse como delito (Agamben, 2002, p. 178).

A arte vem a ser, assim, ao mesmo tempo, instrumento e fruto da legibilidade da história, esta o "único tribunal de justiça que a humanidade atual, ela própria passageira, pode oferecer aos protestos que vêm do passado", nas palavras de Horkheimer (1934 apud Löwy, 2005, p. 50). Ela nasce como que para manter uma memória das glórias desses eventos, mas também para "aplacar as fúrias da memória do mal e velar pela justiça”, na incisiva expressão de Seligmann-Silva (2004, p. 33).

"O passado leva consigo um índice secreto pelo qual é remetido à redenção”, afirma Walter Benjamin (1940 apud Löwy, 2005, p. 48), para indagar em seguida: "Não nos afaga, pois, levemente um sopro de ar que envolveu os que nos precederam? Não ressoa nas vozes a que damos ouvidos um eco das que estão, agora, caladas?" para, então, concluir:

Se assim é, um encontro secreto está então marcado entre as gerações passadas e a nossa. Então fomos esperados sobre a Terra. Então nos foi confiada, assim como a cada geração que nos precedeu, uma fraca força messiânica sobre a qual o passado tem pretensão. Essa pretensão não pode ser descartada sem custo. 
Não seria este o lugar da arte, que visaria, não apenas resgatar uma memória, mas sobretudo atualizá-la em um ato estetica e politicamente presente, recolocando-a, por assim dizer, em movimento?

As manifestações de arte da memória no mundo vêm atualizando os fatos dolorosos que marcaram o século XX e ainda marcam o nosso século XXI, tais como o holocausto, os genocídios, as guerras, as perseguições étnicas, religiosas, e, particularmente no Brasil, têm buscado atualizar, não somente o Estado de exceção aqui instaurado pela ditadura militar, mas também a violência difusa que permeia nossa sociedade, praticada por agentes do Estado, em nome da lei, contra as comunidades pobres e as várias minorias indefesas.

\section{0 antimonumento e o memorial}

Em uma noite de 1939, os militantes nazistas destruíram 104 uma fonte de $12 \mathrm{~m}$ de altura, em Kassel, na Alemanha. Em estilo gótico de forma espiralada-piramidal, instalada na praça da prefeitura, fora construída em 1908 com fundos doados por um empresário judeu daquela cidade, o Sr. Sigmund Aschrott, e assim ficou conhecida como Fonte Aschrott (Figura 1). Mas o presente de um judeu para a cidade era inaceitável pelos nazistas.

Em 1987, Horst Hoheisel ganhou o concurso da Sociedade para Recuperação dos Monumentos Históricos para que, de alguma forma, a fonte e sua história fossem resgatadas. Sua proposta era realizar, no mesmo local, a Fonte Aschrott negativa (Figura 2), invertida, abaixo do nível do solo, com o mesmo perfil da fonte original, uma forma negativa de monumento, que veio a ser uma das manifestações pioneiras de antimonumento, um termo criado posteriormente pelo pesquisador anglo-americano do holocausto, James Young (1992, p. 267). Na ocasião do prêmio, declarou Horst Hoheisel: 
Eu desenhei uma nova fonte como uma imagem especular da antiga fonte, submersa embaixo do lugar da outra, a fim de resgatar a história desse lugar como uma ferida e uma questão em aberto, para penetrar na consciência dos cidadãos de Kassel, para que tais coisas nunca mais se repitam (apud Young, 1992, p. 188; tradução da autora).

"Como relembrar uma ausência? Neste caso, reproduzindo-a, no espaço negativo do monumento ausente”, conclui Young (1992, p. 190).

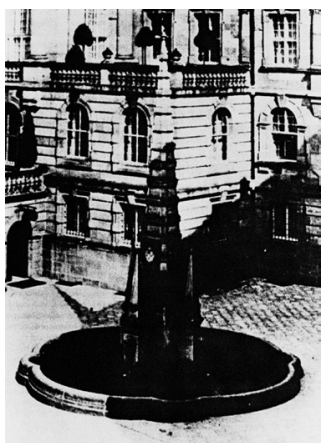

Figura 1 - Fonte Aschrott original, Kassel, c. 1930. Foto de Kassel Kulturamt.



Figura 2 - Fonte Aschrott, forma negativa, Kassel, 1987. Foto de Horst Hoheisel.

\section{A alegoria como memória}

Horst Hoheisel e Andreas Knitz construíram, em 2003, em tamanho natural, uma réplica da ruína do Portal do Presídio Tiradentes (Figura 3), uma estrutura em aço, na forma de gaiola, a que denominaram Pássaro livre / Vogelfrei (Figura 4), e que foi instalada no Octógono da Pinacoteca do Estado de São Paulo.

A ruína localizada na avenida Tiradentes constitui hoje o único remanescente do presídio que fora utilizado pela ditadura militar para encarcerar presos políticos, o qual foi posteriormente demolido para dar existência a uma agência 
de um banco estatal, ao teatro de uma emissora de tevê estatal e às obras do Metrô, em evidente tentativa, por parte do Estado, de apagamento da memória daquele lugar.

$\mathrm{Na}$ gaiola foram encerrados doze pássaros (pombos-correio), os quais, a partir do dia de abertura da exposição, a cada final de semana, eram libertados um a um, para que pudessem voltar para casa, em cerimônia presidida cada vez por um ex-preso político do antigo presídio, que soltava o pombo com as próprias mãos.

Nas palavras de Seligmann-Silva (2004, p. 33):

A ruína do presídio é citada pelos artistas e metamorfoseada em prisão. O portal, local de passagem, por onde inúmeros prisioneiros entraram, e eventualmente saíram, foi transformado em uma alegoria de todo o prédio que ele representa, pars pro totum.



Figura 3 - Ruína do Portal do Presídio Tiradentes, São Paulo, SP, 2002. Foto de Andreas Knitz.



Figura 4 - Horst Hoheisel e Andreas Knitz. Pássaro livre / Vogelfrei, 2003. Réplica do Portal do Presídio Tiradentes construída em aço. Pinacoteca do Estado de São Paulo. Foto de Horst Hoheisel. 


\section{Presença da ausência e atualização da memória}

$\mathrm{O}$ artista argentino Marcelo Brodsky apresentou em 2012, no Memorial da Resistência - Estação Pinacoteca, em São Paulo, a obra denominada Buena memoria (Figura 5), anteriormente apresentada em 2003 no Centro Universitário Maria Antonia da USP, no qual labora sobre foto de sua turma de formatura do Colégio Nacional de Buenos Aires, de 1967. Vários daqueles jóvens, alguns poucos anos depois, foram vítimas da política de "desaparecimento" perpetrada pela ditadura militar argentina, de que foi vítima, inclusive, seu irmão Fernando Rubén, o Nando, retratado quando menino em um tocante ensaio fotográfico de sua mãe Sara (Figura 6), agora ressignificado por Brodsky, que fotografou, também, os rostos dos jovens escolares que visitavam a exposição e que se viam refletidos nos vidros que protegiam as fotos originais. Eram fotos de fotos, uma multiplicidade de tempos e gerações.
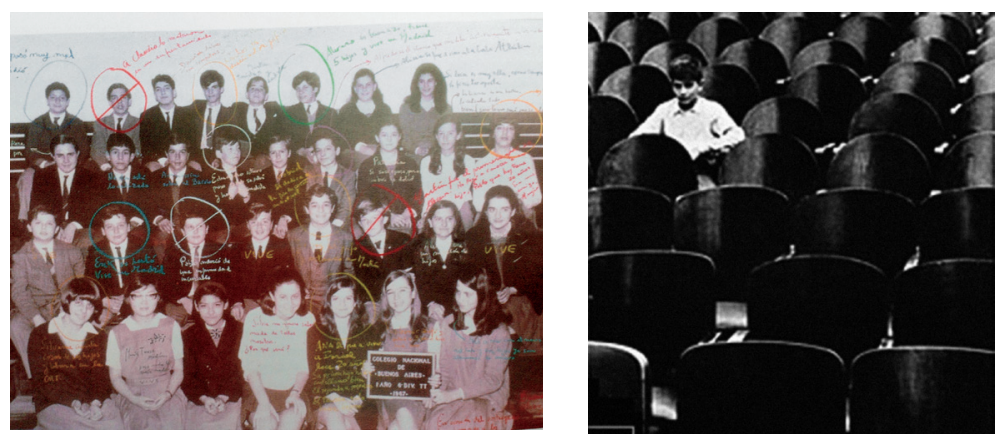

Figuras 5 e 6 - Marcelo Brodsky. Buena memoria, 2003/2012. Centro Universitário Maria Antonia (USP)/Estação Pinacoteca, São Paulo. Obra confecionada com fotos que inclui a de formatura do autor do Colégio Nacional de Buenos Aires, em 1967, e a do irmão Nando desaparecido político ainda quando jovem estudante. Fotos do acervo de Marcelo Brodsky.

\section{A memória como tribunal e redenção}

O artista francês Charles-Eric Gogny concebeu, em 2008, um memorial em vidro, selecionado pelo Conseil National 
pour la Mémoire des Enfants Juifs Déportés para ser instalado em praças e parques de Paris. É uma escultura de vidro plano, com os dizeres e nomes gravados em baixo-relevo pela técnica de verre sablé, que, ao mesmo tempo que é transparente, diáfano, reflete vagamente o observador do presente. É, dialeticamente, uma sobreposição de temporalidades.

Por iniciativa da Association pour la Mémoire des Enfants Juifs Déportés, vêm sendo instalados memoriais em praças e placas em escolas em homenagem às cerca de 11 mil crianças judias deportadas e mortas. Até o presente foram lembradas 6.403 crianças em 332 placas.

Réplicas desse particular trabalho de Gogny (Figuras 7a e 7b), instalado no Parc des Buttes-Chaumont (Paris $19^{\circ}$ ), também foram instaladas nos parques du Temple (Paris $3^{\circ}$ ), Villemin (Paris $10^{\circ}$ ), Léon Serpolet (Paris $18^{\circ}$ ) e Eduard Vaillant (Paris $20^{\circ}$ ), com os nomes das crianças deportadas 108 que viviam em cada um desses bairros. Contêm o texto:

\author{
PASSANTE, LEIA OS SEUS NOMES, TUA MEMÓRIA É \\ A SUA ÚNICA SEPULTURA.
}

No memorial de Buttes-Chaumont, especificamente, são homenageados 33 bebês, de 6 meses a 4 anos, que nunca chegaram a ir à escola, dentre as 423 crianças desse bairro (o $19^{\circ}$ Arrondissement) deportadas para Auschwitz. Nesse vidro se lê também:

PRESAS PELA POLÍCIA DO GOVERNO DE VICHY, CÚMPLICE DO OCUPANTE NAZISTA, MAIS DE 11.000 CRIANÇAS FORAM DEPORTADAS DA FRANÇA DE 1942 A 1944, E ASSASSINADAS EM AUSCHWITZ, PORQUE NASCERAM JUDIAS.

MAIS DE 423 DESSAS CRIANÇAS VIVIAM NO $19^{\circ}$ ARRONDISSEMENT, DENTRE ELAS, 33 BEBÊS QUE NÃO TIVERAM TEMPO DE FREQUENTAR A ESCOLA. 
Mais abaixo, leem-se os nomes e idades de cada bebê...
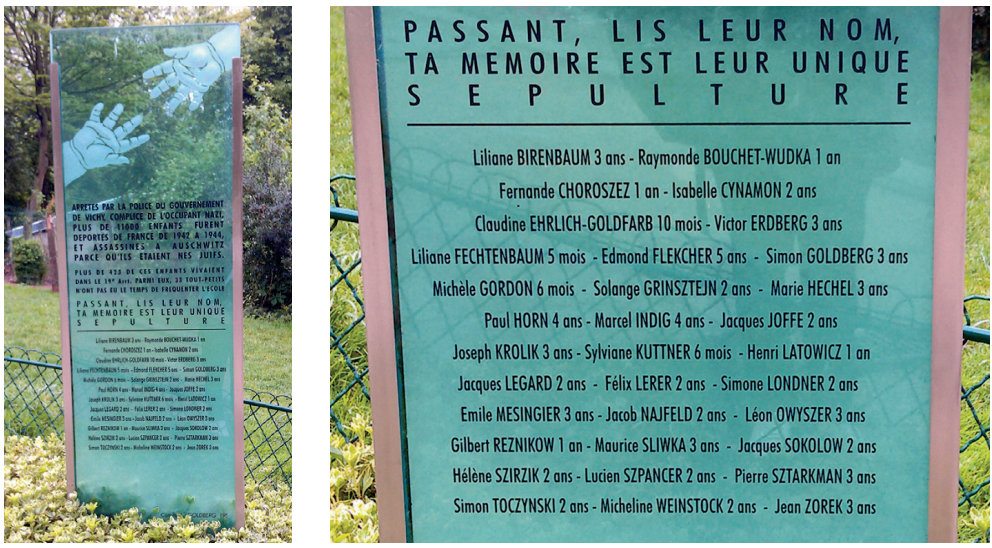

Figuras 7a e 7b - Charles-Eric Gogny. Memoriais em vidro, 2008. Instalados em praças e parques de Paris, França, dedicados às crianças judias francesas deportadas e mortas em Auschwitz. Foto de Cathérine Iffly, 2014.

Essas inscrições fazem um pungente eco às reflexões de Horkheimer: "somente a consciência humana pode se tornar o altar onde a injustiça sofrida pode ser abolida/ ultrapassada" (apud Löwy, 2005, p. 49).

\section{Arte-memória que é pura memória}

Esther Shalev-Gerz, artista lituana-israelense-franco-sueca, criou, em 2005, uma instalação no Grande Hall da Prefeitura de Paris, a que intitulou Entre a escuta e a fala: últimos testemunhos, Auschwitz 1945-2005 (Figura 8). Um trabalho de arte-memória que é pura memória. Foi em comemoração dos 60 anos da libertação do campo de concentração de Auschwitz-Birkenau. Essa instalação constou de 60 monitores de vídeo colocados sobre grandes mesas sinuosas que permitiam aos visitantes, sentados uns em frente aos outros, assistirem os testemunhos de 60 sobreviventes dos campos de concentração nazistas. Os testemunhos desses sobreviventes, gravados em vídeo, em que expunham suas vivências nos campos, pelo tempo 
que quisessem, resultaram em registros de duas a nove horas cada um. A artista entregou-nos os testemunhos como um bem comum, em coerência com a dimensão política e estética de seu trabalho, destaca Didi-Huberman (2012), para concluir que a força desse trabalho está em mostrar os testemunhos sem estetização, sem montagens, angustiantes, em entregar-nos as falas como saíram das testemunhas, com seus "brancos tormentosos":

E como não ver, no filme, nas montagens de Esther ShalevGerz, que os brancos nas palavras são emanações de sofrer, do sofrimento, que vem por assim dizer, envenenar o seu desejo de relato? Mal-estar, impotência, angústia.

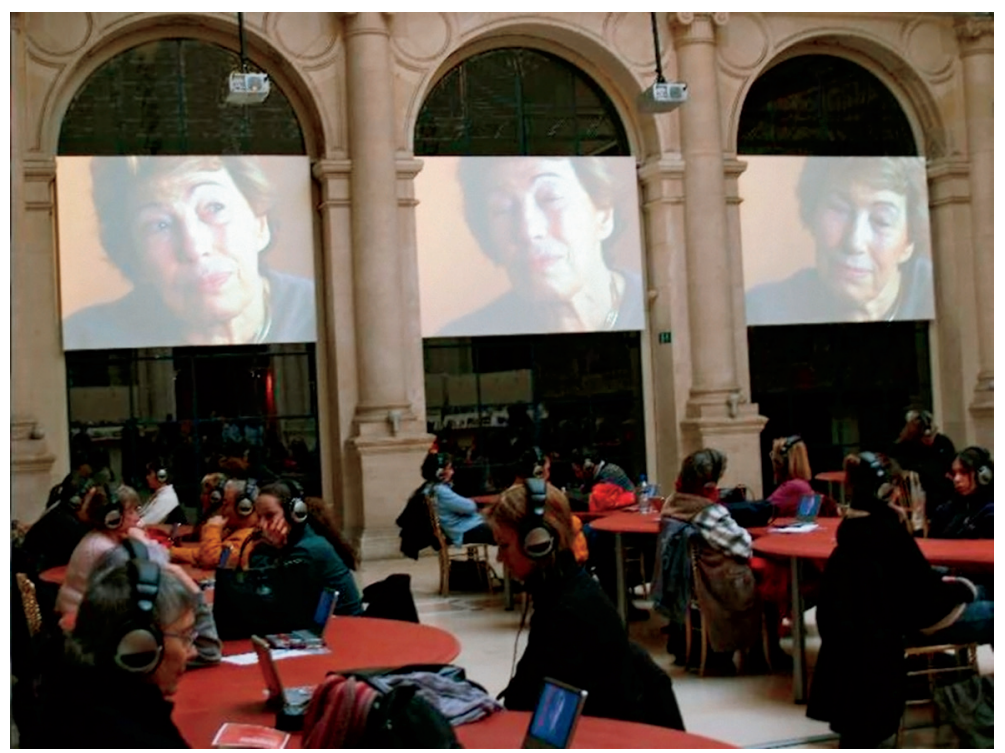

Figura 8 - Esther Shalev-Gerz. Entre a escuta e a fala: últimos testemunhos, Auschwitz 1945-2005, 2005. Prefeitura de Paris, França. Instalação com monitores de vídeo com depoimentos de sobreviventes dos campos de concentração. Foto de Esther Shalev-Gerz. 


\section{A arte como ativação da memória}

Em São Paulo, no Centro Universitário Maria Antonia da USP, Horst Hoheisel e Andreas Knitz, da Alemanha, Marcelo Brodsky, da Argentina, e Fulvia Molina, do Brasil, realizaram, em 2003, uma instalação a que denominaram MemoriAntonia - a alma dos edificios. O foco desse trabalho foi o prédio de número 294 da rua Maria Antonia, pouco antes de ser demolido, onde ocorreram marcantes acontecimentos na cena política e intelectual do país desde a década de 1930. Em 1968, quando ainda era a sede da Faculdade de Filosofia, Letras e Ciências Humanas (FFLCH-USP), fora invadido, depredado e incendiado por forças policiais aliadas às milícias paramilitares do CCC (Comando de Caça aos Comunistas), após intensa batalha com os estudantes que se opunham ao Estado de exceção vigente no país, o que resultou na morte de um jovem estudante e ficou conhecido como a Batalha da Maria Antonia. Esse prédio, assim como o ano de 1968, tornou-se, desde então, um símbolo da resistência democrática na cidade de São Paulo.

Quando os artistas entraram pela primeira vez nos espaços que seriam objeto de sua intervenção, esses espaços se encontravam em estado de profundo abandono, e ainda carregavam traços de sua história. Os artistas trabalharam neles em várias etapas e com metodologias variadas, organizando workshops com jovens artistas, recolhendo testemunhos, fotografando e coletando objetos.

No espaço escuro da instalação, pequenos holofotes, ativados por sensores de presença quando alguém se aproximava, lançavam luz sobre os objetos, pedaços do prédio, tais como vitrais (Figura 9), assoalhos, quadros de luz, extintores de incêndio, vasos sanitários com a pátina de uma densa camada de pó, excrementos e penas de pombos que habitaram o prédio longamente abandonado (Figura 10). Simultaneamente, eram ativados os sons que saíam de 
minialto-falantes espalhados em torno dos objetos: eram vozes, falas de depoimentos (testemunhos de 8 antigos líderes estudantis participantes daqueles acontecimentos, que foram entrevistados em meio aos escombros do espaço que um dia abrigara o Centro Acadêmico da FFLCH). Eram ecos da memória que se misturavam às imagens dos 8 testemunhos mostrados em 8 monitores de tevê, que formavam um semicírculo no chão.

Era a primeira vez que aqueles antigos líderes estudantis ali estavam, depois de 35 anos. Sua emoção transparece nos registros das entrevistas, íntegras, sem cortes e edições, com seus brancos, suas afasias, suas falas trêmulas. Completava a instalação um conjunto de 6 cilindros de vinil transparente, 6 totens (Figura 11) construídos em escala humana, cada um com a foto de um dos estudantes mortos pela ditadura, os quais tinham assinado a lista de presença (Figura 12) da Assembleia Geral do Grêmio da Faculdade 112 de Filosofia (de 9 de setembro de 1966, realizada naquele local). A imagem de cada estudante morto foi sobreposta à imagem da lista de presença na página onde aparecia o seu nome. Pela transparência, essas imagens se misturavam como a memória - de perto, podia-se ler os seus nomes assinados, e, de longe, a figura humana do estudante morto parecia destacar-se, levantar-se: eram como fantasmas. Vindos de onde? Chegando até nós, um contato que nos afetava, um tempo do abraço, o kairós.

O trabalho foi uma espécie de arqueologia da memória: uma ressignificação e atualização de objetos e fragmentos de memória.

A respeito, escreveu Lorenzo Mammì (2004, p. 8):

[...] foi um momento marcante: não apenas por resgatar uma memória, mas sobretudo por atualizá-la em um ato esteticamente e politicamente presente, recolocando-a, por assim dizer, em movimento. 
Foi um ato de ativação da memória, como na feliz expressão de Henri Bergson (1979, p. 71) em que "toda consciência é memória”.
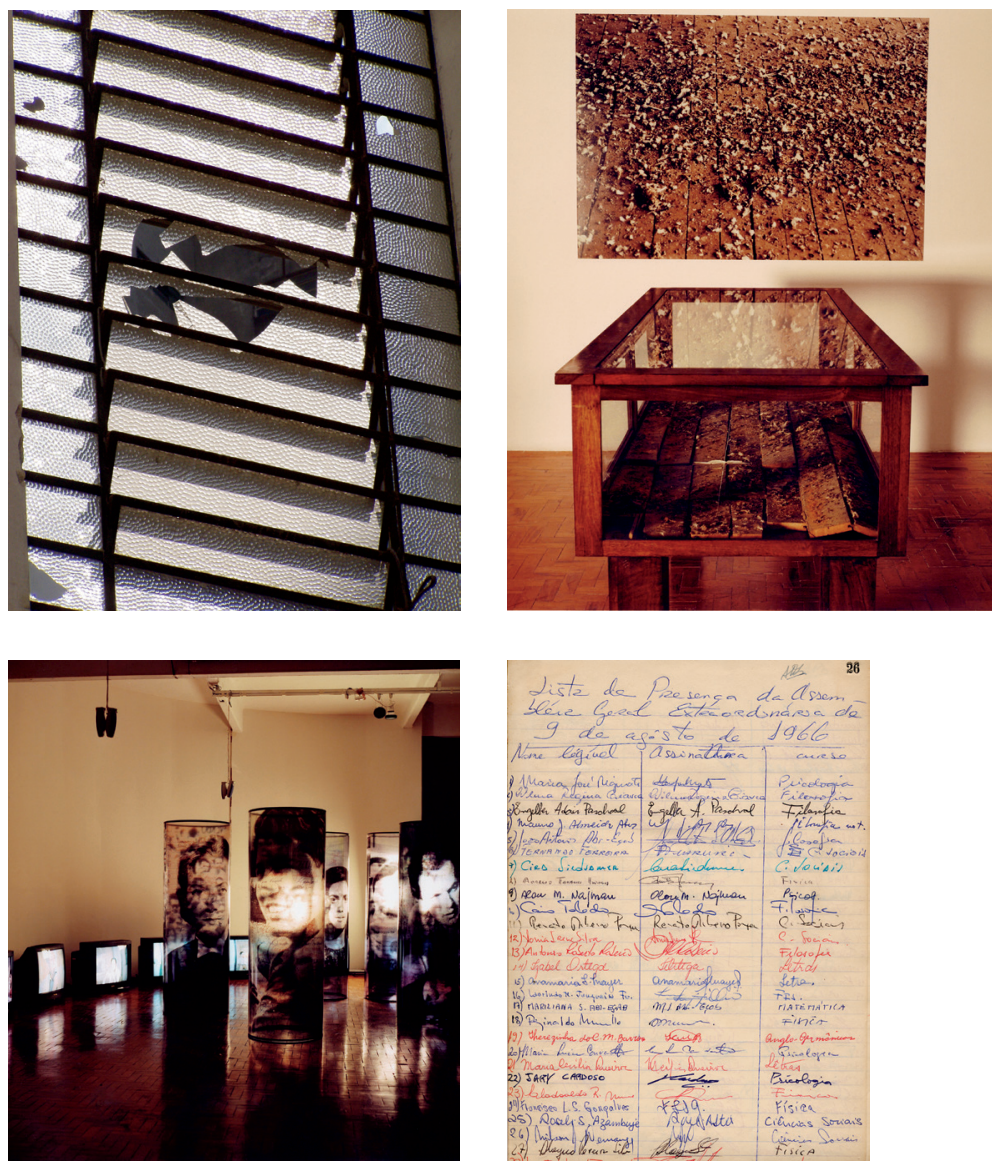

Figuras 9, 10, 11 e 12 - Andreas Knitz, Fulvia Molina, Horst Hoheisel e Marcelo Brodsky. MemoriAntonia - a alma dos edifícios, 2003. Centro Universitário Maria Antonia (USP), São Paulo, SP. Instalação com objetos, documentos e fragmentos do antigo prédio da Faculdade de Filosofia, Letras e Ciências Humanas da USP, na rua Maria Antonia, ícone de resistência na ditadura militar. Inclui totens com fotos de estudantes mortos sobre a imagem da lista de presença de uma assembleia no grêmio estudantil em 1966. Fotos de Fulvia Molina (figs. 9 e 12) e de Marcelo Brodsky (figs. 10 e 11). 
Vemos assim, que a arte vem aportar aos acontecimentos portadores de dor, como desde sempre o fez, a sua razão de consciência, o seu pathos, o seu universo de sensibilidade, o seu afeto, a sua verdade. Vem cumprir um papel ético, o de presentificação do mal que nos fere fundo na alma. Vem elaborar um resgate que se articula com "a exigência de uma salvação, que não consiste simplesmente na conservação do passado, mas que seja também uma transformação ativa do presente", como nos incita Walter Benjamin (apud Gagnebin, 2009, p. 105): "O passado: [é] a história, a rememoração - e o presente: [a] ação redentora” (Benjamin, 1940, p. 53 apud Löwy, 2005).

\section{Fulvia Molina}

é artista, mestre em Artes pela Escola de Comunicações e Artes da Universidade de São Paulo (ECA-USP) e doutora 114 em Ciências pelo Instituto de Biociências da USP.

\section{Bibliografia}

AGAMBEN, G. 2002. Homo sacer: o poder soberano e a vida nua I.

Tradução de Henrique Burigo. Belo Horizonte: Ed. UFMG (coleção Humanitas). 2012. O homem sem conteúdo. Tradução e notas de Cláudio Oliveira.

Belo Horizonte: Autêntica.

BERGSON, H. 1979 [1911]. "A consciência e a vida”. In: LEOPOLDO E

SILVA, F. (coord.). Henri Bergson: cartas, conferências e outros escritos.

São Paulo: Abril Cultural (coleção Os Pensadores).

DIDI-HUBERMAN, G. 2012. "PROYMAGO 5 Georges Didi-Huberman, 15

MAR 2012”. Lisboa: Ymago/Culturgest. Disponível em: <http:/ /www. vimeo.com/43378599>. Acesso em: 3 maio 2015.

GAGNEBIN, J. M. 2009. História e narração em Walter Benjamin. São Paulo:

Perspectiva.

HOMELAND Security Act. 2002. Public Law 107-296. Washington D. C.:

107 th Congress.

LÖWY, M. 2005. Walter Benjamin: aviso de incêndio - uma leitura das teses

"Sobre o conceito de história". Tradução de Wanda Nogueira Caldeira 
Brant, Jeanne Marie Gagnebin e Marcos Lutz Müller. São Paulo: Boitempo (coleção Marxismo e Literatura).

MAMMİ, L. 2004. “O edifício Joaquim Nabuco”. In: KNITZ, A. et al. (orgs.). A alma dos edifícios / Die Seele der Gebäude / The soul of the buildings. São Paulo: Centro Universitário Maria Antonia (USP).

SELIGMANN-SILVA, M. 2004. "A arte de dar face às datas: topografia da memória na arte contemporânea”. In: KNITZ A. et al. (orgs.). A alma dos edificios / Die Seele der Gebäude / The soul of the buildings. São Paulo: Centro Universitário Maria Antonia (USP).

SÓFOCLES. 2012 [c. 440 a.C]. Antígona. Introdução,versão do grego e notas de Maria Helena da Rocha Pereira. Lisboa: Fundação Calouste Gulbenkian.

USA Patriot ACT. 2001. Public Law H. R. 3162. Washington D. C.: 107th Congress.

YOUNG, J. E. 1992. "The counter-monument: memory against itself in Germany today”. Critical Inquiry, v. 18, n. 2, pp. 267-96. 


\section{ARTE, MEMÓRIA E DIREITOS HUMANOS}

FULVIA MOLINA

Resumo: Este ensaio trata de momentos recentes da arte contemporânea em sua relação com os direitos humanos e o resgate da memória dos fatos portadores de dor. São analisadas obras selecionadas de Horst Hoheisel, Andreas Knitz, Esther Shalev-Gertz, Marcelo Brodsky e Fulvia Molina e alguns memoriais de Paris.

Palavras-chave: Antígona; Arte Contemporânea; Razão de Consciência; Razão de Estado; Memória; Direitos Humanos; Memoriais; Antimonumentos.

\section{ART, MEMORY AND HUMAN RIGHTS}

Abstract: This essay adresses recent moments of contemporary art in its relationship with human rights and the memory rescue of painful facts. Selected works from Horst Hoheisel, Andreas Knitz, Esther Shalev-Gertz, Marcelo Brodsky, and Fulvia Molina are analyzed, as well certain Paris memorials.

Keywords: Antigone; Contemporary Art; Reason of Consciousness; Reason of State; Memory; Human Rights; Memorials; AntiMonuments.

Recebido: 31/05/2015 Aprovado: 01/08/2015 